\title{
Predictors of improvement in quality of life and pain relief in lumbar spinal stenosis relative to patient age: a study based on the Spine Tango registry
}

\author{
Rolf Sobottke $^{1,2} \cdot$ Christian Herren $^{3} \cdot$ Jan Siewe $^{2} \cdot$ Anne F. Mannion $^{4} \cdot$ \\ Christoph Röder ${ }^{5} \cdot$ Emin Aghayev $^{5}$
}

\begin{abstract}
Background An open decompression is the most common treatment for lumbar spinal canal stenosis (LSS), even in the elderly. However, it is not clear whether the treatment outcome is age dependent. The main purpose of this study was to evaluate the improvement in quality of life (QoL) and pain relief, after open decompression for LSS in relation to patient age.

Methods The study was performed on the basis of Spine Tango registry data. The database query resulted in 4768 patients from 40 international Spine Tango centres. The patients were subdivided into three age groups: (1) 20-64, (2) 65-74, and (3) $\geq 75$ years. In multivariate logistic regression models, predictors for improvement in QoL and achievement of the minimum clinically relevant change in pain of two points were analysed.
\end{abstract}

On behalf of the Spine Tango Contributors.

Christian Herren

cherren@ukaachen.de

1 Department of Orthopaedic Surgery, Medizinisches Zentrum StädteRegion Aachen GmbH, Mauerfeldchen 25,

52146 Würselen, Germany

2 Department of Orthopaedic and Trauma Surgery, University of Cologne, Joseph-Stelzmann-Straße 9, 50924 Cologne, Germany

3 Department for Trauma and Reconstructive Surgery, University Clinic RWTH Aachen, Pauwelsstraße 30, 52074 Aachen, Germany

4 Spine Centre Division, Department of Research and Development, Schulthess Klinik, Lengghalde 2, 8008 Zurich, Switzerland

5 Institute for Evaluative Research in Medicine, University of Bern, Stauffacherstrasse 78, 3014 Bern, Switzerland
Results All groups benefited from significant improvement in QoL and back and leg pain relief. Age group had no significant influence on the outcomes. The preoperative status of each outcome was a predictor for its own postoperative outcome. Fewer previous surgeries, rigid or dynamic stabilization, and lower patient comorbidity also had a partially predictive influence for one or the other outcome.

Conclusions Our results confirm that all age groups significantly benefit from the open decompressive treatment of LSS. Age group had no significant influence on any outcome.

Keywords Spine Tango - Registry - Spinal stenosis · Decompression · Quality of life · Elderly

\section{Introduction}

The most common age-related change to the spinal column is degenerative erosion which can lead to secondary narrowing of the spinal canal. Neurogenic intermittent claudication, a symptom of lumbar spinal stenosis (LSS), generally develops after the age of 50 [1]. LSS is one of the most widespread degenerative spinal diseases in the elderly. Symptoms can be pronounced enough to severely limit patient mobility. In addition to the typical neurogenic claudication, low back pain, numbness, weakness and tingling in the buttocks and/or thighs are commonly described symptoms, which can lead to psychosocial sequelae such as depression and isolation that impair quality of life [2-4].

Open decompression has become the most common surgical intervention for LSS in elderly patients [5]. If required, decompression may be combined with additional stabilization or fusion. The success of surgical LSS treatment is well documented [6-8]. 
Although the incidence of surgical complications during surgical treatment for LSS is not age dependent, general complications do occur more frequently with increasing age [9]. However, an open decompression still remains a reasonable treatment option even in octogenarians $[5,10]$. Patient age was considered in several studies as a potential predictor for clinical outcome after surgical treatment for LSS [11]. However, the vast majority of the studies included relatively small samples and some studies are relatively old $[5,11]$. The current literature does not provide clear conclusions on the association of patient age with improvement in quality of life (QoL) and pain reduction after surgical treatment for LSS.

The purpose of this study was to assess the improvement in QoL and reduction in pain after open decompression for LSS in relation to patient age.

\section{Materials and methods}

The study was carried out using the Spine Tango data pool and written in accordance with Strengthening the Reporting of Observational studies in Epidemiology (STROBE) statement [12]. Spine Tango, the international spine registry of Eurospine, the Spine Society of Europe is hosted at the University of Bern's Institute for evaluative research in medicine [13]. Within the registry, patient and physicianbased data are gathered in a prospective observational multi-centre manner.

The last three iterations of the Spine Tango surgery form (2005, 2006, and 2011) were used in the analysis. The physician-based forms collect demographic and diagnostic data, previous treatments and surgical details, etc. With regard to the following analysis, all three versions were compatible. The registry also collects outcome data, documented by the patients themselves mostly in the treating centre, but in about one-third of the patients, in the study independently from the treating centre at home. Treating centre collect the filled in forms and either send them to the back office in Bern for scanning or scan them locally if they have an optical marker reader. Among the available outcome instruments, the Core Outcome Measures Index (COMI) questionnaire is the most frequently used one in the registry. The COMI is a short, self-administered outcome instrument consisting of seven questions to evaluate the five dimensions pain, back-related function, symptom-specific well-being, general quality of life and disability (social and work) [14]. Two pain graphic rating scales (GRS $0-10$ points) capture back and leg pain, and all other items use a 5-point adjectival scale. For the summary score, the average of the scores for all five dimensions (each transformed to $0-10$ ) is calculated [14]. The question on quality of life ("Please reflect on the last week. How would you rate your quality of life?", taken from the WHOQoL questionnaire) has five response options: very good, good, moderate, bad, very and bad. At follow-up, an additional question on the patient's assessment of the overall treatment result [Global Treatment Outcome (GTO)] was asked ("Overall, how much did the operation in our hospital help your back problem?"), with five response options: helped a lot, helped, helped only little, did not help, made things worse. For subsequent analyses, the responses on the GTO scale were dichotomised as "good" (operation helped a lot or helped) and "poor" (helped only little, did not help, made things worse). A validated version of the COMI exists in English, German, Italian, French, Spanish, Norwegian, Hungarian, Portuguese, Chinese and Polish.

The study applied the following inclusion criteria: validated version of the COMI in the given country's language, lumbar degenerative spinal stenosis, patient age $>20$ years, no additional spinal pathology (such as deformity, fracture, trauma, spondylolisthesis, inflammation, infection, tumour or failed surgery), decompression with or without rigid stabilization and/or fusion and/or dynamic stabilization, no anterior surgical measures, known ASA classification (American Society of Anaesthesiologists), preoperative and at least one postoperative COMI assessment available between 3 and 30 months (Table 1). If multiple surgeries were available for a patient, only the index surgery for LSS was considered. If multiple follow-up forms were available for a patient within the given follow-up period, the latest form was selected for analysis. Data from Finland, India, Moldova, Netherlands, Singapore, Slovenia, Taiwan, and Turkey were not considered due to the lack of a validated language version of the COMI (5.4\%, Table 1). The selection criteria resulted in 4768 patients from 37 departments from 35 Spine Tango centres from nine countries (Australia, Austria, Belgium, Germany, Italy, Poland, Switzerland, UK, and USA). The proportion of patients with an available COMI at baseline and a postoperative COMI at least 3 months after surgery was $46.0 \%$ in the patient population (Table 1). The patients were subdivided into three socio-economically relevant age groups: (1) 20-64, (2) 65-74, and (3) $\geq 75$ years. Demographic and clinical characteristics of these groups are summarized in Table 1.

\section{Statistical analysis}

Comparisons of preoperative patient characteristics between age groups were performed using Chi square test for nominal data and generalized linear modelling for ordinal data. Comparisons between baseline and follow-up pain levels and quality of life were performed using Wilcoxon signed-rank test and Chi square test, respectively.

Three binomial multivariate logistic regression models were built to analyse predictors of the following outcomes: 
Table 1 Selection algorithm and proportions of excluded data by selection parameter

\begin{tabular}{lrr}
\hline Inclusion criteria & All primary forms (January 2004-March 2015), $N=77,239$ \\
\cline { 2 - 3 } & Included & Excluded (\%) \\
\hline Hospitals with a valid COMI form in the national language & $73,099(94.6 \%)$ & 5.4 \\
Index surgeries & $65,131(89.1 \%)$ & 10.9 \\
Lumbar location (L1/L2-L5/S1) & $47,411(72.8 \%)$ & 27.2 \\
Spinal stenosis & $19,877(41.9 \%)$ & 58.1 \\
No additional pathology & $13,462(67.7 \%)$ & 32.3 \\
Decompression & $13,272(98.6 \%)$ & 1.4 \\
No anterior surgical measures & $11,876(89.5 \%)$ & 10.5 \\
ASA classification known & $10,375(87.4 \%)$ & 12.6 \\
Eligible for $\geq 3$ months follow-up & $10,204(98.4 \%)$ & 1.6 \\
Patient form (COMI) at baseline and at follow-up (3-30 months) & $4768(46.7 \%)$ & 53.3 \\
\hline
\end{tabular}

(1) improvement in quality of life, (2) back pain relief, and

(3) leg pain relief. The improvement in quality of life was dichotomized as "improvement of at least one category" (e.g. from moderate to good or from bad to moderate) or "no improvement or worsening". The back and leg pain relief was dichotomized into achievement vs. non-achievement of a minimum clinically relevant change (MCRC) in back and leg pain of two points on GRS, respectively [15].

As co-variates, age group, sex, ASA classification (1, 2, $\geq 3$ ), extent of lesion (1, 2-3, >3 segments), number of previous surgeries $(0,1,>1)$, most severely affected segment (L1/L2, L2/3, L3/4, L4/5, L5/S1), rigid stabilization (yes/ no), fusion (yes/no) and dynamic stabilization (yes/no), and the duration of COMI interval were included in the regression models. Additionally, QoL response, back and leg pain levels at baseline were considered in the respective models 1-3. Stepwise selection was used in all models.

The level of significance was set to 0.05 throughout the study. All statistical analyses were conducted using SAS 9.4 (SAS Institute Inc., Cary, NC, USA).

\section{Results}

The overall follow-up rate for the COMI assessment in this study population was $46.0 \%$ (hospital-based mean rate $43.7 \%$; lower quartile $22.6 \%$, upper quartile $61.7 \%$ ). The follow-up rate in the age groups (1), (2), and (3) were 42.6, 49.2 , and $50.0 \%$, respectively. Table 2 shows demographic and clinical characteristics of the age groups. The age groups had some significantly different characteristics with regards to ASA classification, extent of lesion, treated segments and the duration of COMI follow-up, though the largest group difference in mean COMI follow-up time was only about 1 month (Table 2). Patients in the oldest age group had greater comorbidity and a greater number of affected segments compared with the other two age groups.
In the youngest age group, the L2/3 segment was less frequently affected and the L5/S1 segment more frequently affected than in the other two age groups.

\section{Postoperative quality of life, back and leg pain relief}

There was no significant difference between age groups in the proportions of patients that improved by at least one QoL category ( $p=0.86)$ and achieved the MCRC in back pain $(p=0.19)$ and leg pain $(p=0.94)$ (Fig. 1$)$.

In all age groups, a significant reduction in back and leg pain, and an improvement in the quality of life was documented ( $p<0.001$ for all outcomes in all groups).

The unadjusted comparisons of patient outcomes in the age groups showed pre- $(p=0.003)$ and postoperative back pain levels $(p<0.001)$ to be different between the age groups, with mean values ranging 5.5-5.9 and 3.3-3.8, respectively. Also, pre- $(p=0.005)$ and postoperative leg pain levels $(p=0.001)$ were different between the age groups, with mean values ranging 6.7-7.0 and 3.3-3.6, respectively. Neither back pain relief ( $p=0.17)$, nor leg pain relief $(p=0.58)$ were significantly different between the age groups (Fig. 2).

The proportion of patients with good GTO was $72.5 \%$ in the youngest, $75.4 \%$ in the mid-age, and $71.6 \%$ in the oldest age group $(p=0.040)$.

\section{Quality of life}

The multivariate logistic regression analysis revealed that worse preoperative quality of life, fewer previous surgeries, lower ASA status (less comorbidity), and the use of rigid stabilization were significant predictors increasing the likelihood of an improvement in quality of life postoperatively with the odds ratios listed in Table 3 . The model required exclusion of 28 patients $(0.6 \%)$ who endorsed very good quality of life at baseline and were not able to improve postoperatively. 
Table 2 Patient characteristics in the age groups

\begin{tabular}{|c|c|c|c|c|c|}
\hline Patient characteristics & (1) 20-64 (years) & (2) 65-74 (years) & (3) $\geq 75$ (years) & Comparison ( $p$ value) & Total \\
\hline$N(\%)$ & $1752(36.7)$ & $1640(34.4)$ & $1376(28.9)$ & na & $4768(100.0)$ \\
\hline Mean age \pm SD (years) & $54.7 \pm 8.5$ & $70.2 \pm 2.8$ & $80.0 \pm 3.6$ & na & $67.4 \pm 11.9$ \\
\hline Age range (years) & $22-64$ & $65-74$ & $75-98$ & na & $22-98$ \\
\hline Females (\%) & 46.8 & 45.9 & 48.0 & 0.51 & 46.8 \\
\hline ASA $1(\%)$ & 35.3 & 12.5 & 4.5 & $<0.001$ & 18.2 \\
\hline ASA $2(\%)$ & 54.6 & 63.6 & 55.7 & & 58.0 \\
\hline ASA > $2(\%)$ & 10.1 & 24.9 & 39.8 & & 23.8 \\
\hline Monosegmental (\%) & 54.9 & 41.9 & 32.4 & $<0.001$ & 43.9 \\
\hline Bi- and trisegmental (\%) & 38.6 & 49.9 & 57.0 & & 47.8 \\
\hline More than three segments (\%) & 6.5 & 8.2 & 10.6 & & 8.3 \\
\hline No previous surgery (\%) & 80.5 & 78.8 & 82.7 & 0.09 & 80.6 \\
\hline One previous surgery $(\%)$ & 14.6 & 16.4 & 12.9 & & 14.7 \\
\hline Two or more previous surgeries (\%) & 4.9 & 4.8 & 4.4 & & 4.7 \\
\hline L1/L2 (\%) & 0.8 & 1.3 & 1.1 & $<0.001$ & 1.0 \\
\hline L2/L3 (\%) & 4.2 & 8.3 & 10.2 & & 7.3 \\
\hline L3/L4 (\%) & 18.3 & 28.2 & 29.6 & & 24.9 \\
\hline L4/L5 (\%) & 56.8 & 52.9 & 51.3 & & 53.9 \\
\hline L5/S1 (\%) & 19.9 & 9.5 & 7.8 & & 12.8 \\
\hline Fusion $(\%)$ & 12.9 & 13.1 & 10.6 & 0.07 & 12.3 \\
\hline Rigid stabilization (\%) & 12.6 & 13.0 & 10.3 & 0.06 & 12.1 \\
\hline Dynamic stabilization (\%) & 8.2 & 9.5 & 7.1 & 0.06 & 8.4 \\
\hline Mean follow-up \pm SD (months) & $15.2 \pm 8.7$ & $16.0 \pm 8.4$ & $16.3 \pm 8.4$ & $<0.001$ & $15.8 \pm 8.5$ \\
\hline
\end{tabular}

na not analyzed, $S D$ standard deviation

Fig. 1 Proportions of patients with an improved quality of life and achieving minimum clinically relevant changes in back and leg pain with $95 \%$ confidence intervals in each of the age groups

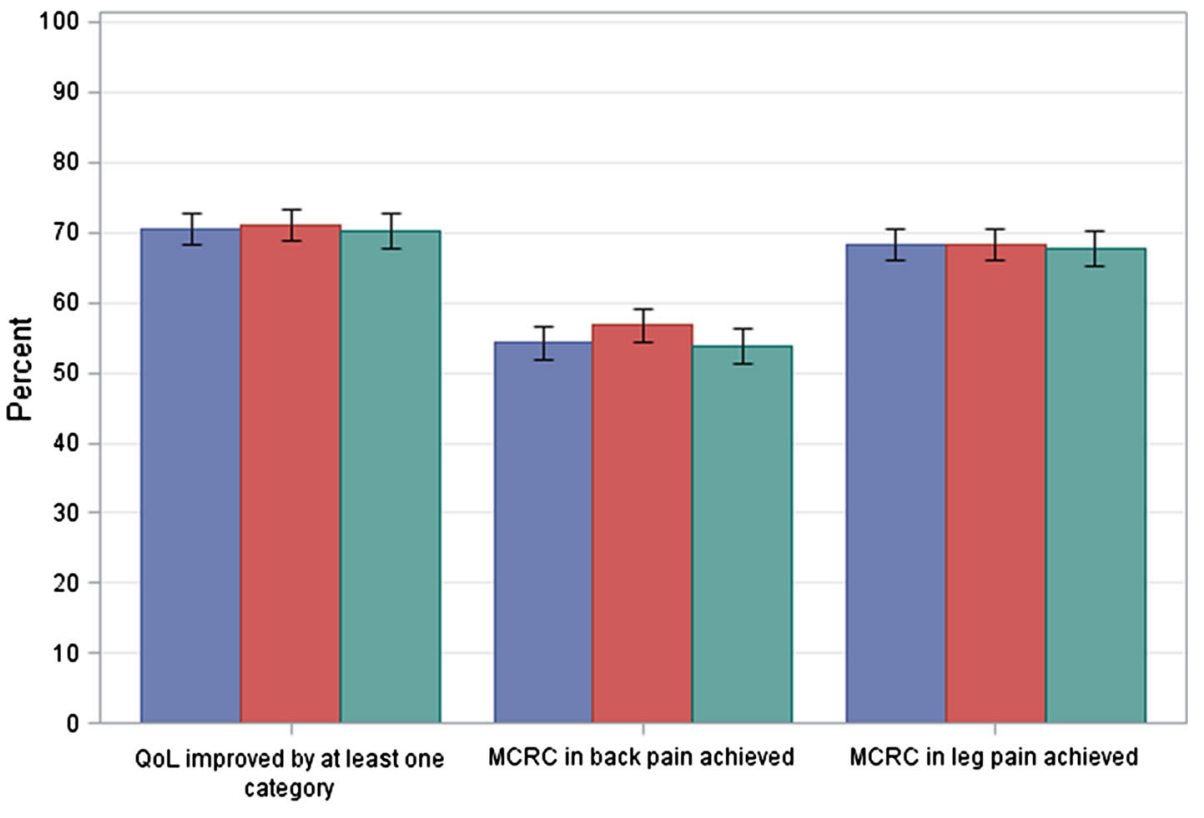

Age group $\square$ 1) $20-64$ yrs $\square$ 2) $65-74$ yrs $\square$ 3) >=75yrs 
Fig. 2 Pre- to postoperative relief of back pain and leg pain with $95 \%$ confidence intervals in the three age groups



Age group $\bullet$ 1) 20-64ys $\bullet$ 2) 65-74ys $\bullet 3$ ) >=75ys

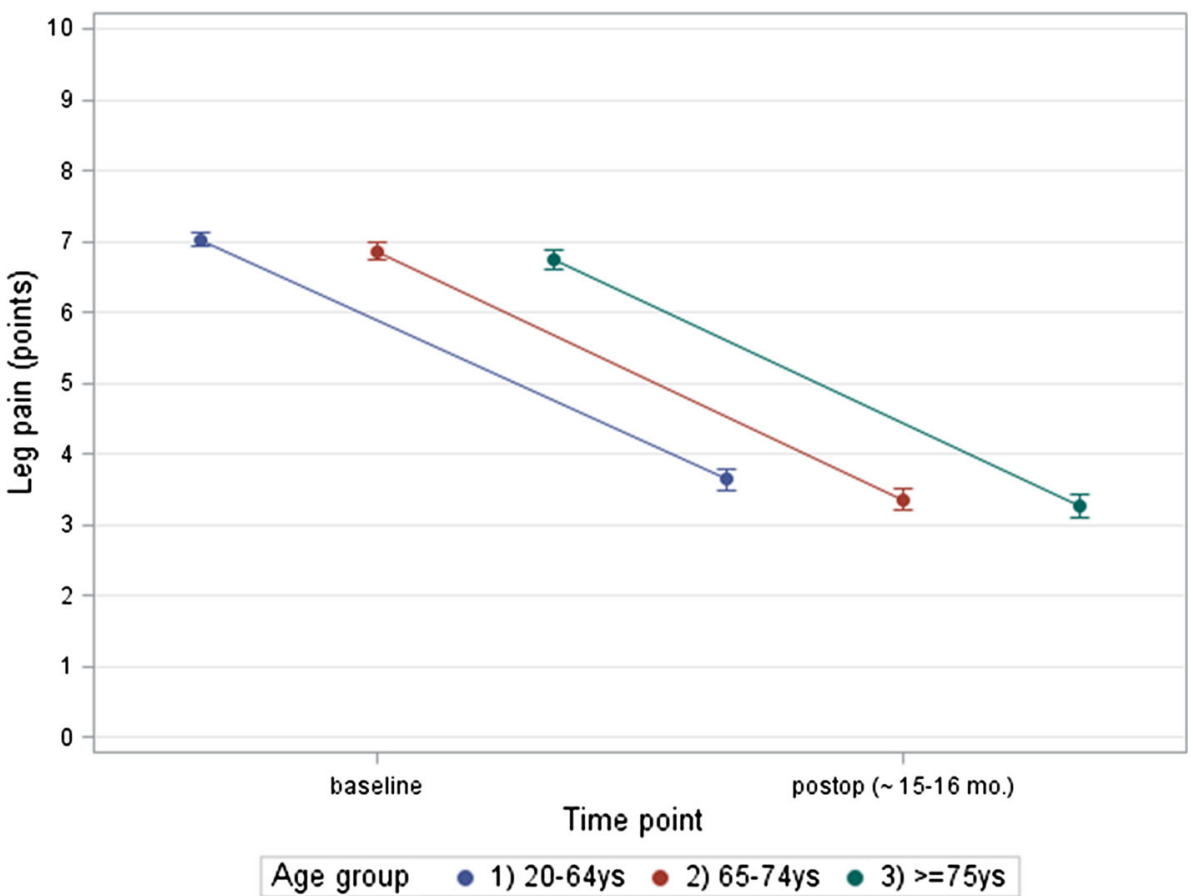

Leg pain

The multivariate regression analysis showed that a higher preoperative leg pain, rigid and dynamic stabilization, and fewer previous surgeries were significant predictors increasing the likelihood of achieving a MCRC in leg pain with the odds ratios listed in Table 5.

Figure 3 demonstrates the average back and leg pain relief vs. continuous age stratified by the postoperative at baseline has different effect in age groups. 
Table 3 Predictors of improvement in quality of life postoperatively of at least one category

\begin{tabular}{lclll}
\hline Co-variate & $p$ value & Effect & OR & $95 \%$ CI \\
\hline Rigid stabilization & 0.017 & Yes vs. no & 1.3 & $1.05-1.60$ \\
ASA classification & 0.002 & 2 vs. 1 & 0.86 & $0.72-1.03$ \\
& & $>2$ vs. 1 & 0.69 & $0.56-0.85$ \\
Number of previous surgeries & $<0.001$ & 1 vs. 0 & 0.73 & $0.61-0.87$ \\
& & $>1$ vs. 0 & 0.55 & $0.41-0.74$ \\
Preoperative QoL & $<0.001$ & Per worse response option & 2.6 & $2.38-2.84$ \\
\hline
\end{tabular}

Probability modelled for postoperative quality of life improvement of at least one category

OR odds ratio, $95 \%$ CI $95 \%$ Wald confidence intervals

Table 4 Predictors of the achievement of a minimum clinically relevant back pain relief of two points

\begin{tabular}{|c|c|c|c|c|}
\hline Co-variate & $p$ value & Effect & OR & $95 \% \mathrm{CI}$ \\
\hline Rigid stabilization & $<0.001$ & Yes vs. no & 1.80 & $1.47-2.22$ \\
\hline Dynamic stabilization & 0.008 & Yes vs. no & 1.38 & $1.09-1.75$ \\
\hline \multirow[t]{2}{*}{ Number of previous surgeries } & \multirow[t]{2}{*}{0.002} & 1 vs. 0 & 0.75 & $0.62-0.90$ \\
\hline & & $>1$ vs. 0 & 0.72 & $0.53-0.98$ \\
\hline \multirow[t]{3}{*}{ Preoperative back pain* age group } & \multirow[t]{3}{*}{0.037} & Per point in age group $=$ (1) $20-64$ years & 1.38 & $1.33-1.44$ \\
\hline & & Per point in age group $=(2) 65-74$ years & 1.44 & $1.38-1.50$ \\
\hline & & Per point in age group $=(3) \geq 75$ years & 1.50 & $1.43-1.57$ \\
\hline
\end{tabular}

Probability modelled for the achievement of the two points

OR odds ratio, $95 \%$ CI $95 \%$ Wald confidence intervals, * interaction

Table 5 Predictors of the achievement of a minimum clinically relevant leg pain relief of 2 points

\begin{tabular}{lcllr}
\hline Co-variate & $p$ value & Effect & OR & $95 \%$ CI \\
\hline Rigid stabilization & 0.028 & Yes vs. no & 1.26 & $1.03-1.54$ \\
Dynamic stabilization & 0.002 & Yes vs. no & 1.49 & $1.16-1.92$ \\
Number of previous surgeries & $<0.001$ & 1 vs. 0 & 0.72 & $0.60-0.86$ \\
& & $>1$ vs. 0 & 0.58 & $0.43-0.78$ \\
Preoperative leg pain & $<0.001$ & Per point & 1.38 & $1.34-1.42$ \\
\hline
\end{tabular}

Probability modelled for the achievement of the two points

OR odds ratio, $95 \%$ CI $95 \%$ Wald confidence intervals
QoL group. It can be observed that the average back pain relief in patients with an improved QoL was two points or more greater than that of patients without any improvement in QoL. Regarding the average leg pain relief, the difference between the groups was even higher, at around three points. Importantly, there were no relevant trends across patient age in any of the QoL groups, for either back pain or leg pain relief.

\section{Discussion}

\section{Patient age and treatment outcome}

All age groups benefited significantly from surgery in terms of pain relief and improved quality of life. There is general consensus that the surgical treatment of LSS in all age groups, including old ( $>65$ years) and elderly ( $>80$ years) patients, significantly improves walking distance [10, 1619], reduces pain [10, 18-23], and decreases consumption of pain killers [18, 19]. Additionally, significant reductions in the need for physiotherapy or other medical treatments [18], as well as significant improvements in Oswestry Disability Index scores [18, 23] and SF-36 scores [22, 23] have been reported.

Several studies addressed the influence of age on the clinical outcome. Aalto et al. performed a systematic review of randomized controlled trials, controlled trials, and prospective cohort studies examining preoperative predictors for clinical outcomes in LSS patients [11]. Eight out of 21 publications were rated as high and 13 as low quality studies. The authors found that age did not 
Fig. 3 Average back and leg pain relief vs. continuous age stratified by the QoL group (improved QoL vs. no change/worse QoL after surgery) with $95 \%$ confidence intervals


influence outcome, and an association between age and postoperative walking ability was observed in only one high quality study [11]. Similarly, other research groups did not identify correlations between age and outcome after surgical treatment of LSS [10, 24]. Recently, Ulrich et al. demonstrated that octogenarians can benefit from a meaningful improvement after lumbar decompression in LSS [5]. However, the mentioned studies had relatively low sample sizes of less than 100 cases. The two largest studies were published in 1998 and included 170 and 257 patients $[25,26]$.

In the present study, postoperative improvement in QoL did not differ significantly between the age groups in either the adjusted or non-adjusted analyses. The age groups were also similar regarding back and leg pain relief in the adjusted and non-adjusted analyses, although preoperatively, the 
groups presented with significantly different back pain levels. Similarly, a single-centre prospective study on 100 patients with one-year follow-up by Thornes et al. reported no significant difference in outcome scores (Swiss Spinal Stenosis Questionnaire and SF-36) in patients older and younger than 65 years. In contrast, older patients were four times more likely to be dissatisfied with the outcome after surgery than the younger ones [27]. Also, in our cohort, a significantly lower proportion of patients in the older group rated their outcome as good in the bivariate comparison among all age groups.

\section{Predictors}

In the current study, the levels of preoperative back pain, leg pain and quality of life had a significant influence on the subsequent postoperative values for the respective parameters. The worse the preoperative status the greater was the likelihood of postoperative improvement. This is a known phenomenon for various outcomes in LSS and in other spinal disorders [24, 28].

Previous surgery had a negative influence on all three outcomes. This may be explained by the fact that patients requiring further lumbar surgery suffer from LSS symptoms potentially for a longer period of time. They are dissatisfied, and need yet another intervention. Szpalski et al. found that back pain sufferers consider themselves to be in generally good health with good QoL, but also noted that patients who had undergone multiple surgeries had a lower opinion of their general health status versus those who had not undergone surgery [29]. Moreover, Saban et al. reported that patients with higher degrees of optimism perceived significantly better QoL and increased fulfilment of expectations [30].

ASA status partially influenced the improvement in QoL. Although the effective difference in the proportion of improved patients between ASA 1 and $>2$ subgroups was only about $2 \%$, the adjusted analysis suggested that low versus severe preoperative comorbidity leads to greater benefits after LSS surgery regarding quality of life.

Patients treated with posterior dynamic stabilization had higher likelihoods of achieving a minimum clinically relevant pain relief for both back and leg pain. Dynamic stabilization aims to retain range of motion of the treated segment without increasing stresses on the adjacent level. This should theoretically promote the recovery of treated segments and prevent degeneration of the adjacent ones. The reports on posterior dynamic stabilization systems are controversial [31-36]. Long-term level I evidence will not be available for many years, so the rationale for utilizing dynamic stabilization will continue to be based on the belief in a theoretical benefit from controlling instead of completely eliminating motion.
The use of rigid stabilization was associated with an increased likelihood of achieving an improvement in quality of life and a clinically relevant improvement in back and leg pain, while fusion itself was not. Being the most invasive surgical approach, instrumented fusion is also the more consequent therapy for segmental instability existing preoperatively or resulting from extensive decompression. Different types of fusion (anterior, posterior, $360^{\circ}$ ) may also lead to different degrees of improvement, but the more complex arthrodeses also have the highest reoperation and complication rates [15, 37]. Consequently, many spine surgeons prefer not to use instrumentation in the absence of gross segmental instability. The study from the Swespine register by Forst et al. did not find additional fusion to improve clinical outcome after decompressive surgery for LSS [38]. Also, an RCT on 229 patients from the same authors did not show any benefits of an additional fusion in comparison with decompression alone [39]. The comparative effectiveness of different surgical approaches was not the focus of this study and the methodology was not appropriate to answer such a question. Therefore, conclusions regarding the potential benefit of one treatment over the other should not be drawn from the current analysis. Further detailed studies comparing main types of treatment for lumbar spinal stenosis in such large cohorts are required.

Additional predictors for poorer subjective outcomes mentioned in the literature include depression, cardiovascular comorbidity, the presence of disorders influencing walking ability, and scoliosis. In turn, better walking ability and self-rated health, higher income, lower overall comorbidity, and pronounced central stenosis predict better subjective outcomes [11]. However, most of these variables were not measured in the present study.

\section{Limitations and strengths of the study}

The major strength of the analysis is the large sample size and routine clinical settings from which the data were drawn. This allows for an accurate detection of significant predictors relevant to the typical type of stenosis surgery performed in daily practice. Particularly in such large cohorts, the clinical relevance and meaningful association of a predictor with an outcome needs to be reported in addition to any statistical significance. At least for the main outcomes and predictors, we consider the observed effects to be clinically relevant. The study population had an overall follow-up rate of $46.7 \%$. Despite multinational registry setting and a large number of participating hospitals, this rate should still be considered as a limitation of the study. Furthermore, data from nine countries were included in the study. Cultural and healthcare system differences may have potentially influenced the results of the 
study. Detailed analyses of countries and individual centres are required to uncover their effects. Also, about two-third of the patients filled in the self-administered COMI at the treating centre during follow-up, as mentioned above. An influence of the physician on the COMI-responses cannot be completely ruled out in these patients, although it would not be expected to have different effects in the different age groups.

The main criticism of medical registries is their unmonitored character, which may lead to a biased capture of the successful cases only. However, there is little reason to believe that a potential selection bias would affect the studied age groups in a differential way, even though the follow-up rate in the youngest age group was about $7 \%$ lower than in the other two age groups. The youngest group had a working age and therefore these patients were potentially less compliant to follow-ups. Patient-rated outcomes were also used in the study, which are less prone to bias. The rates for dural lesions, as the surrogate for a credible documentation, appear to be higher in the Spine Tango than in the Swedish spine registry [15]. Furthermore, a Spine Tango code of conduct was recently introduced to foster honest, transparent, and monitored documentation.

We dichotomized the five response categories for quality of life into improvement of one or more categories vs. no change or worsening. The model required exclusion of 28 patients $(0.6 \%)$ who endorsed very good quality of life at baseline and were not able to improve postoperatively. Alternatively, one could assess the pre-to-postop change more exactly considering the number of improved categories. However, a much larger ceiling effect can be expected in this analysis.

\section{Conclusions}

Our results confirmed that all age groups showed a significant improvement in pain and quality of life after surgical treatment of lumbar spinal stenosis. The level of preoperative back pain, leg pain and quality of life influenced the respective postoperative values. Rigid stabilization and fewer previous surgeries were independent predictors of all three outcomes. Additionally, the comorbidity status partially influenced the improvement in quality of life, and dynamic stabilization influenced back and leg pain relief. As this study was not designed to answer the question of comparative superiority of one treatment over the other, the effects of rigid and dynamic stabilizations as independent predictors for a better surgical outcome should be interpreted with caution. Age group had no influence on the improvement in quality of life or relief of back and leg pain after the surgical treatment of lumbar spinal stenosis.

\section{Key points}

- All age groups showed significant improvements in quality of life and pain after LSS surgery.

- Age group did not influence the extent of improvement in QoL or back and leg pain relief.

- Preoperative levels of back pain, leg pain and quality of life influence their respective postoperative values.

- Fewer previous surgeries increase the likelihood of improvement in pain and QoL.

Acknowledgments All the participants of the Spine Tango Register are acknowledged for their continuous contribution that makes it possible for us to conduct such studies reflecting the daily practice of spine surgeons. The data of the following centres were used (in alphabetic order of country, city, hospital and department): Dept. of Spinal Surgery in Royal Adelaide Hospital (Australia); Dept. of Spinal Surgery in St. Andrew's Hospital in Adelaide (Australia); Dept. of Orthopaedic Surgery in University Hospital Graz (Austria); Dept. of Orthopaedic Surgery in Grand Hôpital de Charleroi (Belgium); Dept. of Orthopaedic Surgery in Edith Cavell Clinic of Brussels (Belgium); Dept. of Orthopaedic Surgery in University Hospital of St. Luc (Belgium); Dept. of Orthopaedic Surgery in Saint Pierre Clinic of Ottignies (Belgium); Dept. of Neurosurgery in Köpenick Hospital DRK Kliniken Berlin (Germany); Dept. of Neurosurgery in University Hospital of Cologne (Germany); Dept. of Orthopaedic Surgery and Traumatology in University Hospital of Cologne (Germany); Dept. of Neurosurgery in Hospital CologneMerheim (Germany); Dept. of Spine Surgery in Hospital Dortmund (Germany); Group Practice of Orthopaedics and Neurosurgery in Hof (Germany); Dept. of Special Spine Surgery in Leopoldina Hospital of Schweinfurt (Germany); Department of Neurosurgery in Sant'Andrea Hospital of the Sapienza University (Italy); Dept. of Orthopaedic Surgery in Orthopaedic and Traumatological Clinic Poznan (Poland); Dept. of Neurosurgery in Specialized Medical Centre S.A. Polanica (Poland); Dept. of Neurosurgery in Medical University Silesia (Poland); Dept. of Neurosurgery in Bethesda Hospital of Basel (Switzerland); Dept. of Spine Surgery in Bethesda Hospital of Basel (Switzerland); Dept. of Neurosurgery in University Hospital of Bern (Switzerland); Dept. of Orthopaedic Surgery in Salem Hospital of Bern (Switzerland); Dept. of Spine Surgery in Sonnenhof Hospital of Bern (Switzerland); Dept. of Orthopaedic Surgery in Cantonal Hospital of Fribourg (Switzerland); Dept. of Neurosurgery in General Hospital of Fribourg (Switzerland); Dept. of Orthopaedic Surgery in Hospital Schwyz (Switzerland); Dept. of Orthopaedic Surgery and Traumatology in Cantonal Hospital of St. Gallen (Switzerland); Dept. of Spine Surgery in The Spine Centre Thun (Switzerland); Dept. of Orthopaedic Surgery in Zollikerberg Hospital (Switzerland); Dept. of Spine Surgery in University Hospital Balgrist of Zurich (Switzerland); Spine Centre Division in Schulthess Clinic of Zurich (Switzerland); Spine Unit of Nuffield Oxford Centre (UK); Dept. of Neurosurgery in Salford Royal NHS Foundation Trust (UK); Dept. of Spine Surgery in Salford Royal NHS Foundation Trust (UK); Dept. of Neurosurgery in The Walton Centre (UK); Dept. of Spine Surgery of Christiana Care Hospital in Newark, Delaware (USA); Division of Spine Surgery in NYU Hospital of New York (USA). 


\section{Compliance with ethical standards}

Conflict of interest None.

\section{References}

1. Porter RW (1996) Spinal stenosis and neurogenic claudication. Spine (Phila Pa 1976) 21:2046-2052

2. Sinikallio S, Aalto T, Airaksinen O, Herno A, Kroger H, Savolainen S, Turunen V, Viinamaki H (2007) Somatic comorbidity and younger age are associated with life dissatisfaction among patients with lumbar spinal stenosis before surgical treatment. Eur Spine J 16:857-864. doi:10.1007/s00586-006-0080-5

3. Vogt MT, Cawthon PM, Kang JD, Donaldson WF, Cauley JA, Nevitt MC (2006) Prevalence of symptoms of cervical and lumbar stenosis among participants in the Osteoporotic Fractures in Men Study. Spine (Phila Pa 1976) 31:1445-1451. doi:10.1097/ 01.brs.0000219875.19688.a6

4. Battie MC, Jones CA, Schopflocher DP, Hu RW (2012) Healthrelated quality of life and comorbidities associated with lumbar spinal stenosis. Spine J 12:189-195. doi:10.1016/j.spinee.2011. 11.009

5. Ulrich NH, Kleinstuck F, Woernle CM, Antoniadis A, Winklhofer S, Burgstaller JM, Farshad M, Oberle J, Porchet F, Min K, LumbSten Research C (2015) Clinical outcome in lumbar decompression surgery for spinal canal stenosis in the aged population: a prospective swiss multicenter cohort study. Spine (Phila Pa 1976) 40:415-422. doi:10.1097/BRS.0000000000000765

6. Amundsen T, Weber H, Nordal HJ, Magnaes B, Abdelnoor M, Lilleas F (2000) Lumbar spinal stenosis: conservative or surgical management?: A prospective 10-year study. Spine (Phila $\mathrm{Pa}$ 1976) 25:1424-1435 (discussion 1435-1426)

7. Malmivaara A, Slatis P, Heliovaara M, Sainio P, Kinnunen H, Kankare J, Dalin-Hirvonen N, Seitsalo S, Herno A, Kortekangas P, Niinimaki T, Ronty H, Tallroth K, Turunen V, Knekt P, Harkanen T, Hurri H, Finnish Lumbar Spinal Research Group (2007) Surgical or nonoperative treatment for lumbar spinal stenosis? A randomized controlled trial. Spine (Phila Pa 1976) 32:1-8. doi:10.1097/01.brs.0000251014.81875.6d

8. Weinstein JN, Tosteson TD, Lurie JD, Tosteson AN, Blood E, Hanscom B, Herkowitz H, Cammisa F, Albert T, Boden SD, Hilibrand A, Goldberg H, Berven S, An H, Investigators S (2008) Surgical versus nonsurgical therapy for lumbar spinal stenosis. N Engl J Med 358:794-810. doi:10.1056/NEJMoa0707136

9. Sobottke R, Aghayev E, Roder C, Eysel P, Delank SK, Zweig T (2012) Predictors of surgical, general and follow-up complications in lumbar spinal stenosis relative to patient age as emerged from the Spine Tango Registry. Eur Spine J 21:411-417. doi:10. 1007/s00586-011-2016-y

10. Shabat S, Arinzon Z, Folman Y, Leitner J, David R, Pevzner E, Gepstein R, Pekarsky I, Shuval I (2008) Long-term outcome of decompressive surgery for lumbar spinal stenosis in octogenarians. Eur Spine J 17:193-198. doi:10.1007/s00586-007-0514-8

11. Aalto TJ, Malmivaara A, Kovacs F, Herno A, Alen M, Salmi L, Kroger H, Andrade J, Jimenez R, Tapaninaho A, Turunen V, Savolainen S, Airaksinen O (2006) Preoperative predictors for postoperative clinical outcome in lumbar spinal stenosis: systematic review. Spine (Phila Pa 1976) 31:E648-E663. doi:10. 1097/01.brs.0000231727.88477.da

12. von Elm E, Altman DG, Egger M, Pocock SJ, Gotzsche PC, Vandenbroucke JP, Initiative S (2007) The Strengthening the Reporting of Observational Studies in Epidemiology (STROBE) statement: guidelines for reporting observational studies. Bull World Health Organ 85:867-872
13. Melloh M, Staub L, Aghayev E, Zweig T, Barz T, Theis JC, Chavanne A, Grob D, Aebi M, Roeder C (2008) The international spine registry SPINE TANGO: status quo and first results. Eur Spine J 17:1201-1209. doi:10.1007/s00586-008-0665-2

14. Mannion AF, Elfering A, Staerkle R, Junge A, Grob D, Semmer NK, Jacobshagen N, Dvorak J, Boos N (2005) Outcome assessment in low back pain: how low can you go? Eur Spine J 14:1014-1026. doi:10.1007/s00586-005-0911-9

15. Munting E, Roder C, Sobottke R, Dietrich D, Aghayev E, Spine Tango C (2015) Patient outcomes after laminotomy, hemilaminectomy, laminectomy and laminectomy with instrumented fusion for spinal canal stenosis: a propensity score-based study from the Spine Tango registry. Eur Spine J 24:358-368. doi:10. 1007/s00586-014-3349-0

16. Jakola AS, Sorlie A, Gulati S, Nygaard OP, Lydersen S, Solberg $\mathrm{T}$ (2010) Clinical outcomes and safety assessment in elderly patients undergoing decompressive laminectomy for lumbar spinal stenosis: a prospective study. BMC Surg 10:34. doi:10. 1186/1471-2482-10-34

17. Benz RJ, Ibrahim ZG, Afshar P, Garfin SR (2001) Predicting complications in elderly patients undergoing lumbar decompression. Clin Orthop Relat Res 384:116-121

18. Galiano K, Obwegeser AA, Gabl MV, Bauer R, Twerdy K (2005) Long-term outcome of laminectomy for spinal stenosis in octogenarians. Spine (Phila Pa 1976) 30:332-335

19. Sanderson PL, Wood PL (1993) Surgery for lumbar spinal stenosis in old people. J Bone Joint Surg Br 75:393-397

20. Cornefjord M, Byrod G, Brisby H, Rydevik B (2000) A long-term (4- to 12-year) follow-up study of surgical treatment of lumbar spinal stenosis. Eur Spine J 9:563-570

21. Arinzon Z, Adunsky A, Fidelman Z, Gepstein R (2004) Outcomes of decompression surgery for lumbar spinal stenosis in elderly diabetic patients. Eur Spine J 13:32-37. doi:10.1007/ s00586-003-0643-7

22. Thome C, Zevgaridis D, Leheta O, Bazner H, Pockler-Schoniger C, Wohrle J, Schmiedek P (2005) Outcome after less-invasive decompression of lumbar spinal stenosis: a randomized comparison of unilateral laminotomy, bilateral laminotomy, and laminectomy. J Neurosurg Spine 3:129-141. doi:10.3171/spi. 2005.3.2.0129

23. Rosen DS, O’Toole JE, Eichholz KM, Hrubes M, Huo D, Sandhu FA, Fessler RG (2007) Minimally invasive lumbar spinal decompression in the elderly: outcomes of 50 patients aged 75 years and older. Neurosurgery 60:503-510. doi:10.1227/01. NEU.0000255332.87909.58 (discussion 509-510)

24. Athiviraham A, Wali ZA, Yen D (2011) Predictive factors influencing clinical outcome with operative management of lumbar spinal stenosis. Spine J 11:613-617. doi:10.1016/j.spinee. 2011.03.008

25. Iversen MD, Daltroy LH, Fossel AH, Katz JN (1998) The prognostic importance of patient pre-operative expectations of surgery for lumbar spinal stenosis. Patient Educ Couns 34:169-178

26. Javid MJ, Hadar EJ (1998) Long-term follow-up review of patients who underwent laminectomy for lumbar stenosis: a prospective study. J Neurosurg 89:1-7. doi:10.3171/jns.1998.89. 1.0001

27. Thornes E, Ikonomou N, Grotle M (2011) Prognosis of surgical treatment for degenerative lumbar spinal stenosis: a prospective cohort study of clinical outcomes and health-related quality of life across gender and age groups. Open Orthop J 5:372-378. doi:10.2174/1874325001105010372

28. Schluessmann E, Diel P, Aghayev E, Zweig T, Moulin P, Roder C, Group SWR (2009) SWISSspine: a nationwide registry for health technology assessment of lumbar disc prostheses. Eur Spine J 18:851-861. doi:10.1007/s00586-009-0934-8 
29. Szpalski M, Nordin M, Skovron ML, Melot C, Cukier D (1995) Health care utilization for low back pain in Belgium. Influence of sociocultural factors and health beliefs. Spine (Phila Pa 1976) 20:431-442

30. Saban KL, Penckofer SM (2007) Patient expectations of quality of life following lumbar spinal surgery. J Neurosci Nurs 39:180-189

31. Stoll TM, Dubois G, Schwarzenbach O (2002) The dynamic neutralization system for the spine: a multi-center study of a novel non-fusion system. Eur Spine J 11(Suppl 2):S170-S178. doi:10.1007/s00586-002-0438-2

32. Schaeren S, Broger I, Jeanneret B (2008) Minimum four-year follow-up of spinal stenosis with degenerative spondylolisthesis treated with decompression and dynamic stabilization. Spine (Phila Pa 1976) 33:E636-E642. doi:10.1097/BRS. 0b013e31817d2435

33. Putzier M, Schneider SV, Funk JF, Tohtz SW, Perka C (2005) The surgical treatment of the lumbar disc prolapse: nucleotomy with additional transpedicular dynamic stabilization versus nucleotomy alone. Spine (Phila Pa 1976) 30:E109-E114

34. Stoffel M, Behr M, Reinke A, Stuer C, Ringel F, Meyer B (2010) Pedicle screw-based dynamic stabilization of the thoracolumbar spine with the Cosmic-system: a prospective observation. Acta Neurochir (Wien) 152:835-843. doi:10.1007/s00701-009-0583-z
35. Grob D, Benini A, Junge A, Mannion AF (2005) Clinical experience with the Dynesys semirigid fixation system for the lumbar spine: surgical and patient-oriented outcome in 50 cases after an average of 2 years. Spine (Phila Pa 1976) 30:324-331

36. Cakir B, Ulmar B, Koepp H, Huch K, Puhl W, Richter M (2003) Posterior dynamic stabilization as an alternative for dorso-ventral fusion in spinal stenosis with degenerative instability. Z Orthop Ihre Grenzgeb 141:418-424. doi:10.1055/s-2003-41568

37. Deyo RA, Martin BI, Kreuter W, Jarvik JG, Angier H, Mirza SK (2011) Revision surgery following operations for lumbar stenosis. J Bone Joint Surg Am 93:1979-1986. doi:10.2106/JBJS.J.01292

38. Forsth P, Michaelsson K, Sanden B (2013) Does fusion improve the outcome after decompressive surgery for lumbar spinal stenosis? A two-year follow-up study involving 5390 patients. Bone Joint J 95-B:960-965. doi:10.1302/0301-620X.95B7.30776

39. Forsth P, Carlsson T, Michaelsson K, Sanden B (2014) No benefits from fusion in decompressive surgery for lumbar spinal stenosis. 2 year results from the Swedish spinal stenosis study, a multicenter RCT of 229 patients. Presented at the Eurospine Meeting, Lyon. Eur Spine J 23(Suppl 25):S495 